\title{
2006-246: PROGRESS ON RAISING THE BAR - ISSUES RELATED TO THE PROHIBITION ON DUAL-LEVEL ACCREDITATION OF ENGINEERING PROGRAMS
}

\section{Ernest Smerdon, University of Arizona}

Dean of Engineering Emeritus University of Arizona 6721 Los Leones Tucson, Arizona 85718 email: ejsmerdon@yahoo.com

\section{Stephen Ressler, U.S. Military Academy}

Vice Dean for Education Office of the Dean U.S. Military Academy West Point, NY 10996 email: Stephen.Ressler@usma.edu

James K. Nelson, University of Texas-Tyler Brazzel Professor and Chair Department of Civil and Environmental Engineering University of Texas at Tyler, 3900 University Boulevard, Tyler, TX 75799 email: jknelson@uttyler.edu

\section{Jim O'Brien, American Society of Civil Engineers} Acting Managing Director, Continuing Education, Educational Activities and Professional Activities, American Society of Civil Engineers, 1801 Alexander Bell Drive, Reston, VA 20191-4400, email: jobrien@asce.org 


\section{Progress on Raising the Bar - Issues Related to the Prohibition on Dual- Level Accreditation of Engineering Programs}

\section{Background}

In an earlier paper on dual-level accreditation, Russell et al. provided information on ASCE's ongoing efforts to reform civil engineering education, such that future civil engineers will be equipped to handle the challenges of professional practice in the decades ahead. ${ }^{1}$ That paper reviewed ASCE Policy Statement 465 (PS 465), which promotes the attainment of a body of knowledge deemed essential to the practice civil engineering at the profession level.. As part of this effort, the society developed a report delineating the body of knowledge (BOK) that future civil engineers will need to have. That report, published in 2004, is currently being updated based on extensive feedback from the initial BOK report. ${ }^{2}$ This revised BOK report should be completed by the end of 2006.

There are many organizations and technology experts who are deeply concerned about how the engineering profession will meet the challenges of the future. Important among these is the National Academy of Engineering, which has recently completed its Engineer of 2020 project. The report on Phase I of the project was discussed by Russell et al. last year and will not be further reviewed here. ${ }^{3}$ While Phase I focused on visions of the problems that engineers would be asked to solve in 2020, Phase II of the study considered the implications of these future conditions for engineering education. The Phase II report, published in 2005, contained 14 recommendations on the education of engineers. ${ }^{4}$ The first two are very closely related to ASCE's PS 465 initiative and are quoted below:

1. The baccalaureate degree should be recognized as the "pre-engineering" degree or bachelor of arts in engineering degree, depending on the course content and reflecting the career aspirations of the student.

2. ABET should allow accreditation of engineering programs of the same name at the baccalaureate and graduate levels in the same department to recognize that education through a "professional" master's degree produces an AME, an accredited "master" engineer.

Recommendation 2 refers to a provision in the ABET Accreditation Policy and Procedure Manual, which states, "Engineering programs may be accredited at either the basic or advanced level ... A program may be accredited at only one level in a particular curriculum at a given institution." This restriction is imposed only by the Engineering Accreditation Commission (EAC). No such prohibition exists in any of the other three commissions of ABET.

The issue of dual-level accreditation is important to ASCE's PS 465 initiative, because PS 465 implementation requires the use of accreditation criteria and processes for validating fulfillment of the BOK. To provide the greatest possible flexibility for civil engineering programs, ASCE is attempting to institute two alternative paths to BOK fulfillment, one involving an ABETaccredited bachelor's degree and one involving an ABET-accredited master's degree. For both 
paths to be fully viable, a given civil engineering program would need to have the flexibility to accredit degree programs at both the basic and advanced levels simultaneously - a practice currently prohibited by ABET's EAC.

The authors know of no documented historical reason for the current EAC restriction on accreditation at two levels. Opposition to dual-level accreditation exists; however, we suggest that this opposition results primarily from misperceptions and from inadequate recognition of the potential benefits of dual-level accreditation. The purpose of this paper is to directly address the principal points of opposition to dual-level accreditation.

The authors of this paper are all actively involved in promoting civil engineering education reform through the implementation of ASCE PS 465. While implementation of PS 465 remains a work in progress, and there are many views on how it should be accomplished, we remain convinced that substantive change is necessary if civil engineers are to adequately meet the nation's technological challenges. Effective change can only occur if artificial constraints on the change process are removed. The prohibition on dual-level accreditation is one such constraint.

\section{A Case in Point: The University of Louisville}

A compelling case for dual-level accreditation can be seen in the challenges faced by the University of Louisville - one of the few U.S. institutions that currently accredits its engineering master's degree programs. Louisville offers both practice-oriented Master of Engineering (MEng) degree programs and research-oriented Master of Science (MS) programs. ${ }^{6}$ The institution has chosen to accredit its MEng programs, while not seeking accreditation for its MS programs. And while Louisville offers bachelor of engineering degrees, and these programs are designed to meet the ABET basic-level criteria, these basic-level degrees cannot be accredited because of the ABET restriction on dual-level accreditation. At a recent meeting of the ABET Engineering Accreditation Commission, Dr. Mickey Wilhelm, Dean of Louisville's Speed School of Engineering, stated that the school would seek accreditation of its engineering bachelor's degree programs if the prohibition on dual-level accreditation did not exist. It is noteworthy that Louisville has no intention of seeking accreditation of its MS degrees. The MS and MEng programs serve distinctly different purposes and student populations; accreditation is deemed to be important for the practice-oriented MEng but not necessary for research-oriented MS.

In considering the pros and cons of dual-level accreditation, it is worthwhile to be mindful of the University of Louisville model - accredited and unaccredited master's degrees offered at the same institution and, in many cases, within the same department.

\section{A Perspective on Dual-Level Accreditation}

Many of the arguments against dual-level accreditation are based on an assumption that a CE department pursuing advanced-level accreditation would be able to offer only accredited master's programs. As noted above, that assumption is incorrect. Like the University of Louisville, many departments are likely to offer accredited and non-accredited programs side by side. There is certainly no prohibition against this practice, as long as the two programs have 
different degree titles. Louisville's pairing of an accredited practice-oriented MEng degree with a non-accredited research-oriented MSCE degree is a logical arrangement that many departments might choose to emulate; however, there is no reason why the two programs would need to be vastly dissimilar. Indeed, a department might reasonably offer accredited and non-accredited MSCE programs that are essentially identical in content. Functionally, the only difference between the two would be that, in the accredited program, graduates' attainment of the basiclevel ABET criteria would need to be validated prior to awarding an accredited advanced level degree.

If one accepts the basic premise that accredited and non-accredited programs can be offered by the same department, then many common arguments against dual-level accreditation vanish. For example, departments' ability to recruit international graduate students will not be limited, since these students will still be able to enroll in the non-accredited degree program. Furthermore, international students who wish to seek licensure in the U.S. will be greatly advantaged by the availability of accredited master's programs. Viewed in this context, the notion that avoiding advanced-level accreditation protects international students is demonstrably false. Denying these students the opportunity to seek accredited master's degrees harms not only the students, but the profession as well.

The notion that accrediting master's programs will limit flexibility or will inhibit a program's ability to focus on non-practice-oriented emerging technologies and interdisciplinary areas is similarly incorrect for two reasons. First, if a department offers both accredited and nonaccredited degree programs, then the department could choose to use the non-accredited degree as the venue for exploring emerging areas. But, more importantly, there is nothing explicitly or implicitly intended in ASCE's current draft Advanced-Level ABET General Criteria that would inhibit the exploration of emerging areas within an accredited degree program.

ASCE's draft Advanced level General Criteria are as follows:

Advanced Level Programs must develop, publish, and periodically review educational objectives and program outcomes. The program must demonstrate that graduates attain, through their educational and professional experiences, knowledge and skills consistent with fulfillment of the basic level general criteria and applicable program criteria (if any). Advanced level programs must consist of at least one academic year of study beyond the basic level. Graduates must have a culminating engineering experience demonstrating advanced level program knowledge.

The requirement for "advanced level program knowledge" was written explicitly to provide maximum flexibility in defining the advanced level specialization area. The current draft ASCE Commentary emphasizes this point as follows: "Civil engineering specializations in nontraditional, boundary, or emerging fields such as ecological engineering and nanotechnology are encouraged."7 In the authors' opinion, the advanced-level criteria will promote and encourage, rather than limit, flexibility. Indeed, attendees at the 2005 National Civil Engineering Department Heads Meeting strongly endorsed these criteria - a good indicator that the concerns about inflexibility are unwarranted.

Another concern expressed is that accrediting master's programs will significantly increase the time and resources required for programs to prepare for accreditation visits. However, while it is 
certainly true that some additional resources will be required, the increase is not likely to be as significant as many believe. For regional accreditation (SACS, MSACS, etc.), departments are already required to assess their graduate programs. Most programs that choose to accredit their engineering master's programs will probably continue to accredit their bachelor's degree programs as well — and thus will be able to use the assessment and continuous improvement processes already in place. Accreditation visits for basic and advanced-level programs will normally be done at the same time; thus the program will be able to prepare for both simultaneously. Moreover, it is likely that there will be only a single self-study report. Most importantly, the draft accreditation criteria and associated guidelines have been designed to minimize the incremental resource requirements for advanced-level accreditation. For example, as the current draft ASCE Commentary states, "Successful project reports, theses, or comprehensive exams approved by the faculty are some of the possible ways the program might demonstrate that its graduates have the ability to apply advanced knowledge."7 Thus, there is no reason for any new assessment processes above and beyond those already existing in the current degree programs. Compliance with the requirement for advanced-level specialized knowledge can be demonstrated, for example, with a master's thesis or report approved by the faculty.

Department heads and deans often express the concern that allowing dual-level accreditation will result in market pressures on CE departments to accredit their master's programs. This is entirely possible; but is it really a serious concern, if accrediting a master's program is not the onerous burden it is often claimed to be? A more important question may be: are market forces necessarily bad? Market pressures have always driven product development and innovation in the United States. There is no reason that this would not also be true for advanced-level education, provided the accreditation criteria accommodate curricular innovation. And they do, as noted above.

It is often claimed that allowing dual-level accreditation would force the accreditation of master's programs in states that mandate accreditation in all circumstances where opportunities for accreditation exist. In an effort to validate or refute this claim, ASCE conducted a survey of civil engineering department heads during the past year. The survey was administered via the CE department heads listserv. Department representatives of 36 unique programs located in 30 different states responded to the request. In response to the question "Do you know of any state that would mandate accreditation of both an institution's basic level and advanced level engineering program?" 34 responded "No," and two responded "I do not know."

In response to the question "Is there any other non-statutory mandate that would require your institution to seek dual level accreditation if the prohibition were lifted?" 27 responded "No," and eight responded "I do not know". One responded that he had been told by several members of his state licensing board that, should the prohibition on dual level EAC accreditation be lifted, his program should seek dual level accreditation of the CE programs to allow for those advanced-level graduates without a basic-level accredited degree to seek professional licensure. A respondent from another state noted that his state might choose to mandate accreditation of some advanced level programs to allow for licensing of graduates who did not have accredited basic level degrees. But, significantly, no survey respondent noted any state requirement which mandated that if any accreditation is available for a program, then the program must seek that accreditation. 
It is worth noting that some states do mandate accreditation-Louisiana, for example. But in this case, institutions are required to accredit either bachelor's or master's-level programs. Even if dual-level accreditation were available, there would be no requirement to accredit both.

Recognizing that it is difficult to prove a negative, the authors certainly do not deny that state mandates might exist. We just have not been able to find any yet. Any specific references documenting such mandates are welcome.

\section{Final comment}

Finally, in considering this issue, the authors suggest that civil engineering educators look beyond departmental and institutional interests and consider the broader impact on the civil engineering profession. Dual-level accreditation is not an end in itself. It is a means of facilitating flexibility and opportunity for programs to innovate in engineering education. From an ASCE perspective, it assists in "Raising the Bar." The ultimate goal of this initiative is to better prepare graduates to practice civil engineering at the professional level in the $21^{\text {st }}$ century. What could be more important?

The authors are interested in hearing from you. Are there other concerns or considerations that have not been addressed in this paper? Please send your comments to the authors.

\section{References}

1. Russell, Jeffrey S., Ernest T. Smerdon and Thomas A. Lenox, 2005. It's Time to Remove a Barrier to Engineering Education Reform: ABET's Prohibition on Dual Level Accreditaion. Proceedings of the 2005 Annual Conference and Exposition, June 12-15, 2005, Portland, Oregon.

2. ASCE Body of Knowledge Committee, 2004. Body of Knowledge for the 21st Century. ASCE.

3. Russell, lo cit.

4. NAE Committee on the Engineer of 2020, Phase II, 2005. Educating the Engineer of 2020 - Adapting Engineering Education to the New Century. National Academy of Engineering.

5. ABET Accreditation Policy and Procedures Manual, Effective for Evaluations During the 2006-2007 Accreditation Cycle. ABET. Accessed at http://www.abet.org/forms.shtml, January 16, 2006.

6. "Quick Facts." J.B. Speed School of Engineering, University of Louisville. Accessed at http://speed.louisville.edu/cms/content.php?q areaprimaryid $=2 \& q \_$areasecondaryid $=7 \& q \_$areatertiaryid $=0 \& q$ areaq uaternaryid $=0 \& q$ areatertiaryidexpand $=0$, March 1, 2006.

7. "Commentary on the ABET Engineering Criteria for Civil and Similarly Named Programs - Version 2.2 (Draft as of April 2, 2005)." Accessed at http://www.asce.org/pdf/ASCECommentaryv22Apr05.pdf, March 1, 2006. 